\title{
Fabrication, characterisation and low-velocity impact testing of hybrid sandwich composites with polyurethane/layered silicate foam cores
}

\author{
James Njuguna $^{1 *}$, Sławomir Michałowski ${ }^{2}$, Krzysztof Pielichowski $^{2}$, Kambiz Kayvantash $^{1}$ and \\ Andrew C. Walton ${ }^{3}$ \\ ${ }^{1}$ Centre for Automotive Technology, Department of Sustainable Systems, Cranfield University, \\ Bedfordshire MK43 0AL, UK \\ ${ }^{2}$ Department of Chemistry and Technology of Polymers, Cracow University of Technology, \\ ul. Warszawska 24, 31-155 Kraków, Poland. \\ ${ }^{3}$ Cranfield Impact Centre, Cranfield University, Bedfordshire MK43 0AL, UK
}

\begin{abstract}
A series of nanophased hybrid sandwich composites based on polyurethane/montmorillonite (PU/MMT) has been fabricated and characterised. Polyaddition reaction of the polyol premix with 4,4'-diphenylmethane diisocyanate was applied to obtain nanophased polyurethane foams which were then used for fabrication of sandwich panels. It has been found that the incorporation of MMT resulted in higher number of PU cells with smaller dimensions and higher anisotropy index (cross-sections RI and RII). The obtained materials exhibited improved parameters in terms of thermal insulation properties. The results also show that nanophased sandwich structures are capable of withstanding higher peak loads than those made of neat polyurethane foam cores when subject to low-velocity impact despite lower density than that of neat PU foams. This is especially significant for multiimpact recurrences within the threshold loads and energies studied.
\end{abstract}

Keywords: Nano-reinforced composites, polyurethane nano-foams, nanoclay, sandwich structures

*Corresponding author: j.njuguna@cranfield.ac.uk, Tel. +44 1234 754186, Fax: +44 1234752473 (J. Njuguna). 


\section{Introduction}

Sandwich composites are used in a wide range of applications from aircraft, ships, ballistic vests and helmets through to racing car and high-end sports cars to provide a range of functions including structural stiffness, crash energy management, heat shielding and many others. These structures, composed of a core of cellular material and outer composite skins, are lightweight and yet offer high resistive stiffness against traction, compressive and bending loads. These properties are utilised to produce functional structures that must sustain high stresses under normal conditions. During severe impact loads in automotive applications, for example, these structures must dissipate impact energy to protect either the rest of the structure or the vehicle occupants.

Research has shown that damage initiation thresholds and damage size in sandwich composites depend primarily on the properties of the core materials and facings and the relationship between them. Much of the early research on sandwich composites under impact focused on honeycomb core (Nomex, glass thermoplastic or glass-phenolic) sandwich constructions. A key problem in honeycomb sandwich construction is the low core surface area for bonding [1-3]. Consequently, expanded foams, (often thermoset) are now preferred to achieve reasonably high thermal tolerance, though thermoplastic foams are also used. In turn, the response of foam core sandwich constructions to impact loading has been studied by many researchers [4-6]. Accordingly, it is now well understood that the response of foam core sandwich composites strongly depends on the density and the modulus of the foam.

A possible way of improving the properties of foam materials is through the inclusion of small amounts of nanoparticles (carbon nanotubes and nanofibres, $\mathrm{TiO}_{2}$, nanoclay, etc.) to improve the foam density and modulus properties. Up to now, montmorillonite (MMT) nanoclays have been the best candidate for foam reinforcement due to ease of processing, enhanced thermal-mechanical properties, wide availability and cost $[7,8]$. Likewise, polyurethanes (PU) are core materials of choice due to their tailorable and versatile physical properties, ease of manufacture and their low costs. The use polyurethanes filled with nanoparticles to construct either laminates or foams is relatively new. Moreover, the use of nanoparticles in such laminates [9], or foams in sandwich composite construction, is in its infancy but has been found to be both realistic and beneficial [10]. For instance, 
by using less than $5 \%$ by weight of nanoclay loadings, significant improvement in foam failure strength and energy absorption has been realised with over a 50\% increase in the impact load carrying capacity when compared to a neat foam sandwich $[11,12]$. However, since most current research concentrates on the processing and characterization of nanophased foams and evaluation of static properties only, dynamic materials data on impact failure mechanisms and impact property relations is missing. For the application of nanophased foams in sandwich constructions for ballistic resistance, a proper understanding of their impact behaviour at both high and low-velocity impact is required.

Therefore, by taking advantage of the emerging new materials, nanophased sandwich structures have been fabricated and tested for low-velocity (up to $7 \mathrm{~m} / \mathrm{s}$ ) impact resistance in this study. This work builds on our previous investigations into sandwich composites [13, 14], montmorillonite [7, 8] and on polyurethanes [15-17]. A feasible application for these lightweight structures that we are currently researching is in energy absorbing structures [14] or as inserts in hollow structures [18] in car bodies. Importantly, these foams can also be selectively stiffened to meet specific requirements.

\section{Polyurethane nanofoams}

Foams are defined as materials containing gaseous voids surrounded by a denser matrix, which is usually a liquid or solid. Polymer foams can also be defined as either closed cell or open cell foams. In closed cell foams, the foam cells are isolated from each other and cavities are surrounded by complete cell walls. In open cell foams, cell walls are broken and the structure consists of mainly ribs and struts. Generally, closed cell foams have lower permeability, leading to better insulation properties. Open cell foams, on the other hand, provide better absorptive capability. One-step reactive foaming is typical for thermoset polymers. A good example is PU/clay nanocomposite foams, where a physical blowing agent such as pentane is used with monomers and clay nanoparticles and the exothermic reaction leads to a temperature jump and foaming. Most nanocomposite foams to date are synthesized via a two-step process: the nanocomposite is synthesized first and this is followed by foaming. Readers interested in the synthesis of PU/clay foams are referred to the available literature such as Refs. [19, 20] (literature related to the reactive extrusion foaming of various nanocomposites is also covered). Polymeric 
foams have been widely used as packing materials because they are lightweight, have a high strength/weight ratio, superior insulating properties and high energy absorbing performance.

Polyurethane (PU) foams account for the largest global market (approx. 53\%) among polymeric foams and have a remarkably broad range of applications including thermal insulation, cushioning, buoyancy, energy absorption (packaging) amongst many others. Their low density also permits the design of light, stiff components such as aircraft-interior panels, structural shapes (transform cores, bulkhead cores, stringers) in fibre-reinforced plastic (FRP) boat building, impact-limiters and crashpads, composite foam cores, mould-patterns and plugs. The mechanical properties of PU foams are important considerations for such structural and semi-structural applications. Unlike thermoplastic foams, PU foams are formed by reactive processing in which polymerization and foam blowing occurs simultaneously. In this process, polymer structure must build up rapidly to support the fragile foam, but not too fast to stop bubble growth.

The effects of clay type, clay content, and PU molecular structure on clay dispersion in PU nanocomposites have been studied in the literature [7, 8]. It has been found that MMT clays exchanged with long chain onium ions (carbon number $>12$ ) have good compatibility with polyol. The extent of gallery expansion of modified MMT is mainly determined by the chain length of the gallery onium ions. A good dispersion of layered silicate has been found to improve PU elastomer nanocomposites in terms of their mechanical properties, thermal stability and gas permeability. Good dispersion of clays in the PU matrix has been achieved through the modification of MMT with active surfactants containing more than two hydroxyl groups. The presence of hydroxyl groups enhance intra-gallery polymerisation, which in turn leads to better clay dispersion. However, the morphology of nanocomposites prepared by this approach is still a combination of exfoliation/intercalation and the method only works at low clay content, i.e. less than $3 \mathrm{wt} . \%$, even for organoclay modified by surfactants with three hydroxyl groups. The exfoliated clay dispersion has only been observed at low reaction rates in solution polymerization.

The effects of nanoparticles on mechanical properties of PU/clay nanocomposite foams have also been investigated in the literature $[19,20]$. It is well known that H-bond formation among urethane groups, greatly contributes to the strength and modulus of PUs. The overall performance of PU nanocomposite 
foams depends on the competition between the positive effects of clay on polymer reinforcement and foam morphology, and the negative effects on H-bond formation and network structure.

Currently there are only a few studies in the literature regarding the use of nanoclay in the reactive PU foaming process [19]. Several patents on PU nanocomposite foams claim significant property improvement such as improved compressive strength, thermal insulation [21], and fire retardance [22]. However, relatively few details are provided in the literature. Lee et al [19], described the preparation and characterization of PU nanocomposite foams and they found that the clay dispersion was affected by the foaming process. With the inclusion of $5 \%$ functional organoclays, nanocomposite foams showed a higher cell density with a smaller cell size. Depending on the chemical structure of polyurethane, a $650 \%$ increase in compressive strength was observed in PU nanocomposite foam with relative low crosslinking density and urethane content. However, the opposite effect was observed in PU nanocomposite foams with highly crosslinked structure and high urethane content [23].

\section{Experiments}

\subsection{Synthesis of nanophased foams}

In this study, polyurethane foam with different weight percentages (up to 10\%) of nanoclay were prepared. The low weight percentages were targeted for infusion to avoid the agglomeration of nanoparticles common in high concentrations. Preparation of the PU systems modified with MMT consisted of three steps - first, polyol blend (polyether RF-551) and polyester (T-425R) mixture from Alfasystems, Brzeg Dolny, Poland, was stirred with powdered MMT (Optibent 987, Süd Chemie AG, Moosburg, Germany). Then catalyst (N,N-dimethyl cyclohexylamine), water and surfactant (SR-321, Union Carbide, Marietta, GA) were added in order to prepare the polyol premix (component A). In the next step, n-pentane as a physical blowing agent was added to component A. Component B was polymeric 4,4'-diphenylmethane diisocyanate (PM 200). It was added to component A and the mixture was stirred for 10 seconds with an overhead stirrer. Finally, the prepared mixtures were dropped into a mould. All the experiments were performed at ambient temperature of $c a .20^{\circ} \mathrm{C}$. 


\subsection{Fabrication of sandwich panels with nanophased cores}

The sandwich beam samples were fabricated from aluminium face sheets (Grade 24139, Young's modulus of $79 \mathrm{GPa}$ and thickness of $2 \mathrm{~mm}$ ) combined with $20 \mathrm{~mm}$ thick nanophased polyurethane rigid foams outlined in Section 3.1. Firstly, the aluminium faceplates were pre-treated and polished. Later they were degreased using acetone for 2 minutes before applying the adhesive (DP-100 supplied by $\left.3 \mathrm{M}^{\circledR}\right)$. The surfaces were then dried and the adhesive applied evenly on the foam surface using a glue gun and the metal skin applied on top. This was repeated for the remaining side of the foam after allowing for 24 hours of curing time. Once the adhesive was applied, the sandwich samples were cured for a further period of 24 hours in a press. The samples were laid on the base of the press between two thick metal plates to ensure pressure was distributed evenly across the adhered surface. The finished products consisted of 5 specimens of sandwich beams of length $140 \mathrm{~mm}$ and width 100 $\mathrm{mm}$ for each.

\subsection{Characterisation}

Optical microscopy analyses were performed using a PZO optical microscope equipped with vision track. Aphelion software was used to analyse cells' geometry. Scanning electron microscopy (SEM) images were acquired with a Zeiss EVO 50 SEM.

A Netzsch thermogravimetric analyzer TG 209 was used to investigate the thermal stability of the obtained PU/MMT nanofoams. The samples were heated in an open $\alpha-\mathrm{Al}_{2} \mathrm{O}_{3}$ pan, from $30^{\circ} \mathrm{C}$ up to $650^{\circ} \mathrm{C}$ at a heating rate of $10^{\circ} \mathrm{C} / \mathrm{min}$ under air atmosphere.

All the low impact tests were conducted using an instrumented falling weight impact device (drop tower). The device was equipped with data acquisition system to acquire force versus time data. Using this machine, impact energy and velocity can be varied by changing the mass and height of the dropping weight. The velocity of the falling drop mass is measured just before it strikes the specimen. It is also fitted with pneumatic rebound brake, which prevents multiple impacts on the specimen. During the testing, the specimen is held in the fixture placed at the bottom of the drop tower which provided a clamped circular support span (Figure 1). The weight of cross-head is maintained at a 
specific value and it is guided through two frictionless guide columns. The impactor end of the drop mass is fitted with an instrumented tup with a hemispherical end having a capacity to record the transient response of the specimens. To carry out the impact tests, sandwich composite samples $(140 \mathrm{~mm} \times 100 \mathrm{~mm})$ were placed between the clamps and the height was adjusted depending on the desired energy level. The projectile had a $20 \mathrm{~mm}$ diameter hemispherical tip. The transient force signal obtained during the test was measured using a piezo-electric load cell located above the impactor tip and was routed through an amplifier and logged against a time-base.

\section{Results and discussions}

\subsection{Cell structures analysis}

SEM analysis shows that with increasing content of nanofiller cells become smaller and regular distribution prevails (Table 1).

\section{Table 1}

Cell distribution perpendicular to the direction of growth is denser in comparison to that of the parallel direction of growth.

The cell structure of foams modified by MMT was investigated by use of Aphelion ${ }^{\mathrm{TM}}$ software. A series of pictures obtained by an optical microscope, showing the cell structure of foams with different MMT content, is presented in Figure 1.

\section{Figure 1}

The anisotropy index, mean area and number of cells in the MMT-modified polyurethane systems were determined. Due to the anisotropic structural properties of materials resulting from the forced growth of the foam, materials were characterized in three directions (one perpendicular and two 
parallel to direction of foam growth). A schematic representation of the methodology of structural investigation is presented in Figure 2.

Figure 2

In the case of PU foams modified with MMT, an increase of anisotropy index for two parallel directions (RI and RII) was observed. The maximum values were observed at MMT content of $7.5 \mathrm{wt}$. $\%$ (Table 2).

Table 2

The incorporation of MMT resulted in a higher number of cells with smaller dimensions and higher anisotropy index (cross-sections RI and RII). The obtained materials exhibited improved parameters in terms of thermal insulation properties [24]. The investigated structural properties are expected to correlate with mechanical properties, combustibility behaviour and thermal conductivity. Further studies are under way in order to estimate these structure-property relationships.

The number of cells per square millimeter and their shape (the anisotropy index) is a critical parameter that strongly influences the thermal insulating properties of foamed materials. As the number of cells increases, the coefficient of thermal conductivity decreases [24]. Regarding the anisotropy index, with increasing values the heat flow decreases providing that the heat flow direction is perpendicular to cell height (the longer cell dimension). The foaming method affects the cell structure of foams, particularly the mould shape and dimensions. During the foaming process elongation of cells in the direction of foam growth is observed depending on type of mould. The introduction of montmorillonite into the polyurethane foam resulted in an increased number of cells and higher anisotropy index. Therefore better thermal insulation properties could be expected for the obtained foams and this will be the subject of our next studies.

\subsection{Thermal stability}

The decomposition process can be divided into three steps as shown on Figure 3 and these are associated with complex structural arrangement of the PU materials. 
Figure 3

It is known that the energy of dissociation of the urethane groups is influenced by the substituents (structural units) bound to oxygen and nitrogen atoms in the urethane group. Reported research shows that the upper stability temperatures for the different urethane groups depends on their activation energy and lay between 120 and $250^{\circ} \mathrm{C}$ [15-17]. Besides, thermal studies on polyurethane materials are complicated by one or more of the following effects: (i) specific intermolecular interactions via hydrogen bonding, (ii) crystallinity, and (iii) the presence of chemical crosslinking. All three effects may influence the nature and extent of thermal decomposition, and the possibility of inhibiting it by using thermal stabilizers.

Changes of the thermal stability of PU/MMT systems are caused by suppression of the molecular mobility of polymer chains by MMT layers (Figure 4).

Figure 4

Molecular mobility is the major factor that contributes to the transport of reactive species within the polymer. On the other hand, MMT stacks can reduce the rate of volatiles' release from the material, which results in changes of the thermal stability as well. Further detailed studies on these effects are underway.

\subsection{XRD Results}

The dispersion state of montmorillonite in PU matrix was evaluated by means of the X-ray diffraction (XRD) method. It was observed that the regular arrangement of MMT layers was maintained in PU foams and diffraction peaks were displayed at about 5.8 and $6.0 \mathrm{deg}$ (Figure 5).

Figure 5 
The interlayer distance in PU materials increased slightly compared with neat MMT (Table 3) due to intercalation of the polymeric component.

Table 3

SEM microphotograph confirms that MMT is fully exfoliated in the PU matrix as demonstrated on Figure 6.

Figure 6

\subsection{Low velocity impact tests}

The impact response of sandwich structures with and without nanoclay core and nanophased face sheets were evaluated. Several samples of each set were tested at different energy levels. Transient data including time, load, energy, velocity and deflection were collected for each sample as functions of time. Figure 7 compares typical load and deflection versus time curves for the four specimen types at $45 \mathrm{~J}$ impact energy level.

\section{Figure 7}

The peak loads were $3560 \mathrm{~N}$ for neat cored sandwich and for $2.5 \%$ MMT loaded core sandwich composites. A slight improvement of $\sim 300 \mathrm{~N}$ was observed in peak load for both $5 \%$ and $7.5 \%$ MMT loaded samples, indicating that higher MMT loading samples performed better than the lower MMT loaded ones despite their lower density as compared to neat PU foams.

The energy absorption at the failure point was recorded as $32.5 \mathrm{~J}, 32.5 \mathrm{~J}, 43.4 \mathrm{~J}$ and $44 \mathrm{~J}$ for $0 \%, 2.5 \%$, 5\% and 7.5\% MMT loading respectively. The energy absorption in any material under impact loading is mainly through the elastic deformation in the initial stage with some energy absorbed through friction. Once, the energy level is beyond the level required for maximum elastic deformation, the 
structure then dissipates the excess energy in the form of either plastic deformation in the case of ductile materials or through various damage mechanisms in the case of brittle materials. As can be seen in Figure 8, it is evident that the absorbed energy at peak load was within a narrow range for all samples.

Figure 8

The deflection at peak load is a qualitative indication of the stiffness of the material. The same applies to their maximum recorded deflection, which averaged around $2.1 \mathrm{~mm}$ with minor diversity between the specimens. As expected, the peak loads and deflections were similar at low impact energy. These current results were in contrast to the related published work which reported that at $45 \mathrm{~J}$, the neat core sandwich structures had higher deflection at peak load in nanophased core and fibre-reinforced sandwich composites [25]. It is further reported in the literature that the total time and the time to peak load are also higher for the neat core sandwich samples [25]. However, it should be noted that this work was based on fibre-reinforced composites as face sheets whereas aluminium face sheets with no indent striker perforations have been used in the current work.. It is also apparent that we will need to undertake future tests at higher energy levels, above the $45 \mathrm{~J}$ thresholds of the current tests.

A detailed examination revealed no debonding of the skin and core or crack development into the foam cross-section at the mid-plane of the structures over the range of energies considered. This demonstrated the importance of a proper selection of adhesive for particular foams. Typically, core fracture takes place when defects exist in the adhesive layer and at the skin/adhesive/core interfaces or where poor adhesion occurs between the skin and the adhesive, in our case, DP- $100^{\circledR}$ which yields a thin and highly viscous film. The significance of how the impact resistance of sandwich panels is related to fabrication techniques has been addressed by Abrate [26]. When a one-step process is used to cure the facings to the core, localized cell wall collapse and cell coalescence occur, leading to nonuniform thickness and weaker cores near the skin/core bondline. In such cases, the problem is caused by the high pressure required to cure the facings. In the current work, therefore, a thin layer application was employed followed by compression during bonding hence minimising potential 
defects in the materials at the fabrication stage. Nevertheless, a microscopic inspection revealed some small debonding for both $5 \%$ and $7.5 \%$ samples at the skin/foam interface edges in the structure width after the first impact tests. This failure may be attributed to parameters that are direct indications of the stiffness of the samples rather than just the adhesive failure. It follows that at impact, as the dented aluminium face sheet yielded inwards, the back face remained intact and no deformations were observed along the cores length. However, debonding occurred along the sandwich composite edges (face plate, width-wise) to make up for the bending displacements thereby forcing the edge lines to split along the skin/core interface. The core at the midsection experienced compression forces but there were no signs of crack formation on any of the samples even under microscopy. This may be related to reactive foams where the microcellular cells collapse to absorb load instead of exhibiting the expected cracks and fracture characteristics, that are widely reported in the literature.

Since sandwich structures are often used as energy absorbing structures in damage susceptible areas, we decided to conduct a second drop weight impact recurrence on the previously impacted samples in order to closely replicate repetitive occurrences. Such scenarios are common between structural inspection periods or in incidences where the damage was missed during normal inspection routines. Interestingly, we found that the nanophased samples recorded significantly higher peak loads than the neat PU cored ones. As can be seen from Figure 9 and 10, a difference of over $1000 \mathrm{~N}$ in peak load was observed for the $7.5 \%$ samples compared with that of neat PU foam samples.

\section{Figure 9}

Figure 10

It was further noted that the neat foam samples had the highest energy intake at failure point, in agreement with previous observations by Hosur et al. [25]. Still, there was no visible cracking deformation on the surface of the reactive foam cores along the length of the structures. The only visible debonding and crack formation was along the width of the structures which, as alluded to earlier, may be associated to bending deformation on the face plate due to impact loads. Further 
investigations by microscopy are currently underway to investigate the level of damage to the crosssections of the microcellular cores in conjunction with in-depth morphology studies.

\section{Conclusions}

Nanophased reactive polyurethane cores were manufactured and then used to fabricate sandwich structures. It has been found that the incorporation of MMT resulted in a higher number of PU cells with smaller dimensions and higher anisotropy index (cross-sections RI and RII). The obtained materials exhibited improved parameters in terms of thermal insulation properties. The investigation revealed that nanophased sandwich structures were capable of taking higher peak loads than those made of neat polyurethane cores when subject to low-velocity impact. This was especially true for multi-impact recurrences within the threshold loads and energies studied. It is proposed to investigate the threshold load that initiates delamination damage in the sandwich laminate which is a particularly important property of polymer composite components exposed to water and/or moisture and subjected to low energy impact. 


\section{References}

1. A. T. Nettles, and A. J. Hodge, National SAMPE Symposium and Exhibition (Proceedings). 35, $1430(1990)$.

2. J. Gustin, M. Mahinfalah, G. N. Jazar, and M. R. Aagaah, Exp. Mech., 44, 574(2004).

3. P. M. Schubel, J. Luo, and I. M. Daniel, Compos Part A., 36, 1389(2005).

4. G. Caprino, and R. Teti, Compos. Structur., 29, 47(1994).

5. T. Anderson, and E. Madenci, Compos. Struct., 50, 239(2000).

6. J. R. Banerjee, J. Njuguna, R. Morishima, M. Perera, and C. Cheung, $47^{\text {th }}$ AIAA/ASME/ASCE/AHS/ASC Structures, Structural Dynamics, and Materials Conference, 1 - 4 May 2006, Rhode Island, USA, 2006.

7. A. Leszczyńska, J. Njuguna, K. Pielichowski, and J. R. Banerjee, Thermochim. Acta., 453, 75(2007).

8. A. Leszczyńska, J. Njuguna, K. Pielichowski, and J. R. Banerjee, Thermochim. Acta., 454, 1(2007).

9. J. Njuguna, K. Pielichowski, and J. R. Alcock, Adv. Eng. Mater., 9, 835(2007).

10. J. Njuguna, K. Pielichowski, and D. Desai, Polym. Adv. Techn.,19, 947(2008).

11. A. A. Mohammed, M. V. Hosur, and S. Jeelani, Cell Polym., 25, 293(2006).

12. M.F. Uddin, H. Mahfuz, S. Zainuddin, and S. Jeelani, In: SEM Annual Conference and Exposition on Experimental and Applied Mechanics, Jun 7-9 2005. Portland, United States; 2005.

13. J. R. Banerjee, C. W. Cheung, R. Morishima, M. Perera, and J. Njuguna, Inter. J. Solids Struct., 44, 7543(2007). 
14. J. Njuguna, P. Wambua, T. Jackson, S. Liesker, S. Monoogian, G. Salazar, and E. Schuivens, In: Fibre Reinforced Composites, 2007, Port Elizabeth, South Africa, 9 -12 December 2007; 2007.

15. K. Pielichowski, D. Slotwinska, and E. Dziwinski, J. Appl. Polym. Sci., 91, 3214(2004).

16. K. Pielichowski and D. Slotwinska, Thermochim. Acta., 410, 79(2004).

17. K. Kulesza, and K. Pielichowski, J. Anal. Appl. Pyrolysis., 76, 249(2006).

18. S. Glaser. ATZ Automotive Technology, June, 54(2008).

19. L. J. Lee, C. Zeng, X. Cao, X. Han, J. Shen, and G. Xu, Compos. Sci. Technol., 65, 2344(2005).

20. X. Cao, L. James Lee, T. Widya, and C. Macosko, Polymer, 46, 775(2005).

21. J. E. Kresta, J. H. Wu, and R. M. Crooker, EP 1209189 A1, 2006.

22. G. C. Lees, C. M. Liauw, A. N. Wilkinson, A. McIntyre, and D. Burrows, UK Pat. Appl., GB, 2400107; 2004.

23. X. Cao, L. J. Lee, T. Widya, and C. Macosko, Polymer., 46, 775(2005).

24. A. Prociak, Cell structure - thermal conductivity relationships of polyurethane and polystyrene foams. Fifth International Conference on Foam Processing \& Technology, FOAMS 2006, Chicago, USA, Conference Proceedings on CD, 2006.

25. M. V. Hosur, A. A. Mohammed, S. Zainuddin, and S. Jeelani, Compos. Struct., 82, 101(2008).

26. S. Abrate, Impact on composite structures. New York: Cambridge University Press; 1998. 


\section{Caption of Tables and Figures}

\section{Tables}

Table 1 SEM micrographs for nanoinduced foams studied

Table 2 Structural properties of the PU/MMT foamed nanomaterials.

Table 3 XRD result of the PU/MMT foamed nanomaterials

\section{Figures}

Figure 1 Cell structure of modified PU/MMT foamed materials: a), b), c), d), e) perpendicular; f), g), h), i), j) parallel I; k), 1), m), n), o) parallel II to the direction of foam's growth)

Figure 2 Test surfaces; $\mathrm{P}$ - perpendicular, RI and RII parallel to the direction of foam growth

Figure 3 TG results for PU/MMT foams

Figure 4 DTG curves for PU/MMT foams investigated

Figure 5 Diffraction patterns of the PU/MMT foamed nanomaterials.

Figure 6 SEM microphotograph confirms that MMT is fully exfoliated in the PU matrix

Figure 7 Comparison of load vs time graph obtained from first impact

Figure 8 Energy vs time graph obtained from first impact

Figure 9 Load vs time graph obtained from second impact test

Figure 10 Energy-time graphs after second impact test 
Table 1 SEM micrographs for nanoinduced foams studied

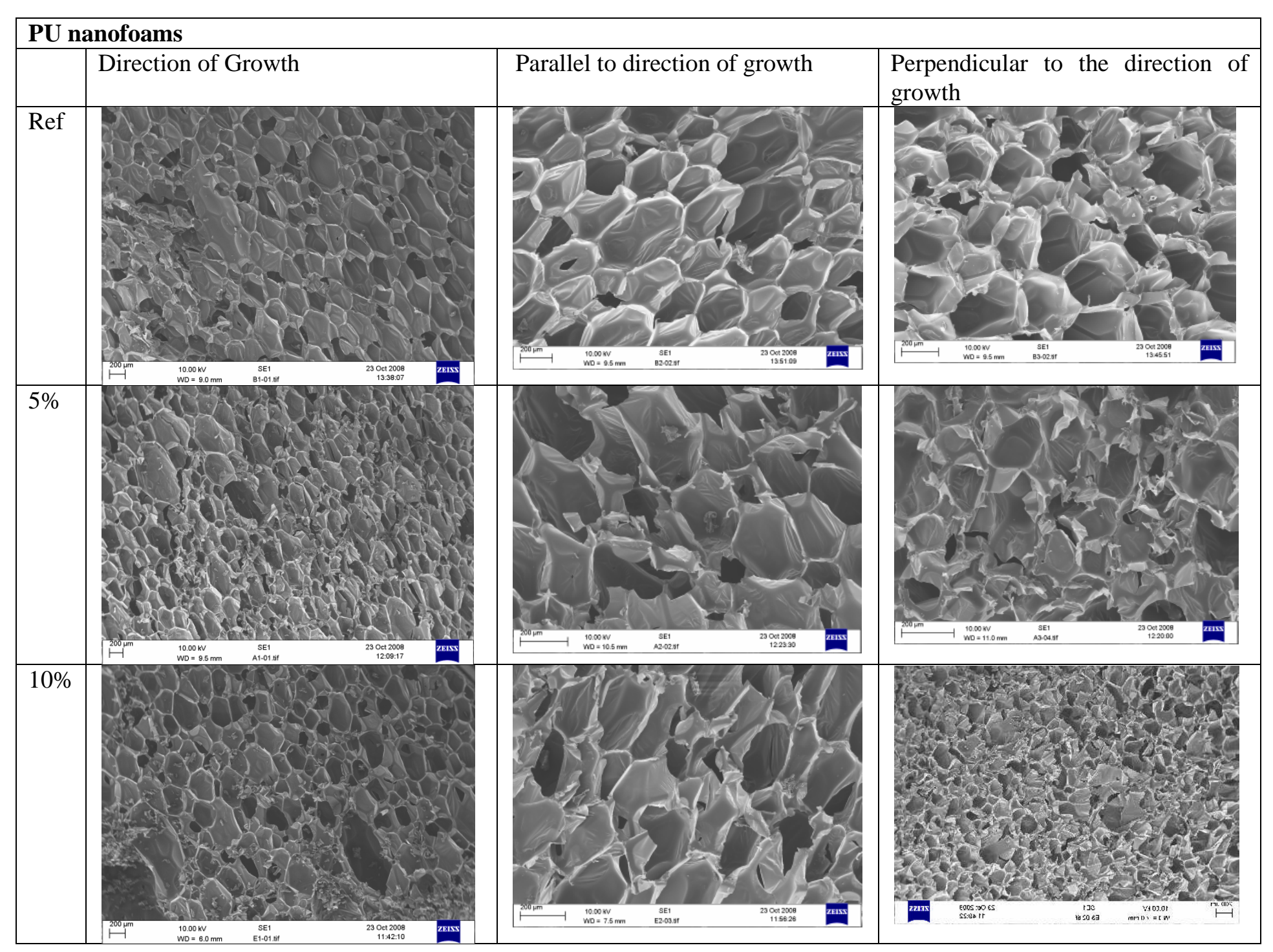


Table 2 Structural properties of the PU/MMT foamed nanomaterials.

\begin{tabular}{|c|c|c|c|c|c|}
\hline Cross-section & $\begin{array}{l}\text { MMT content } \\
\text { [wt. \%]* }\end{array}$ & $\begin{array}{l}\text { Average } \\
\text { number of } \\
\text { cells }\end{array}$ & $\begin{array}{l}\text { Average } \\
\text { surface of cells } \\
{\left[\mathrm{mm}^{2}\right]^{* 10^{-3}}}\end{array}$ & $\begin{array}{l}\text { Anisotropy } \\
\text { coefficient }\end{array}$ & $\begin{array}{l}\text { Apparent } \\
\text { density } \\
{\left[\mathrm{kg} / \mathrm{m}^{3}\right]}\end{array}$ \\
\hline \multirow{5}{*}{$\begin{array}{l}\text { Perpendicular } \\
\text { (P) }\end{array}$} & - & 125 & 4.82 & 1.02 & 46.3 \\
\hline & 2.5 & 125 & 4.28 & 1.20 & 44.8 \\
\hline & 5.0 & 173 & 2.95 & 1.12 & 42.9 \\
\hline & 7.5 & 191 & 2.82 & 1.15 & 43.3 \\
\hline & 10.0 & 177 & 2.56 & 1.07 & 44.1 \\
\hline \multirow{5}{*}{$\begin{array}{l}\text { Parallel I } \\
\text { (R I) }\end{array}$} & - & 109 & 5.83 & 1.34 & \\
\hline & 2.5 & 96 & 5.23 & 1.70 & \\
\hline & 5.0 & 126 & 4.74 & 1.65 & \\
\hline & 7.5 & 131 & 4.26 & 1.70 & \\
\hline & 10.0 & 129 & 4.62 & 1.38 & \\
\hline \multirow{5}{*}{$\begin{array}{l}\text { Parallel II } \\
\text { (R II) }\end{array}$} & $\overline{-}$ & 96 & 6.23 & 1.27 & \\
\hline & 2.5 & 111 & 5.11 & 1.49 & \\
\hline & 5.0 & 128 & 4.86 & 1.64 & \\
\hline & 7.5 & 111 & 5.20 & 1.65 & \\
\hline & 10.0 & 113 & 5.25 & 1.58 & \\
\hline
\end{tabular}

"The amount of modifier (in regard to the mass of reference foam) in wt. \% 
Table 3 XRD result of the PU/MMT foamed nanomaterials

\begin{tabular}{|c|l|}
\hline $\begin{array}{l}\text { MMT } \\
\text { content } \\
\text { [wt. \% }]\end{array}$ & $\begin{array}{l}\text { 2theta } \\
\text { degrees }\end{array}$ \\
\hline 100 & 6.35 \\
\hline 2.5 & 5.90 \\
\hline 5.0 & 6.00 \\
\hline 7.5 & 5.80 \\
\hline 10.0 & 6.00 \\
\hline
\end{tabular}




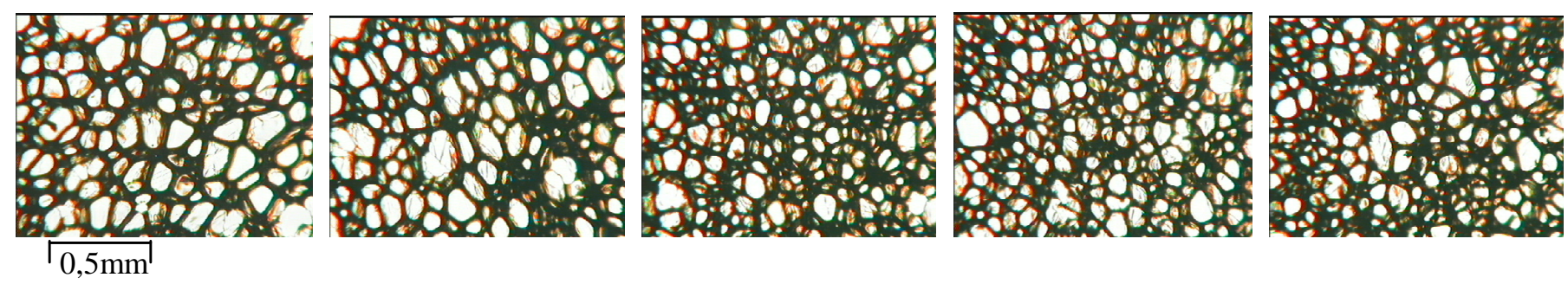
a) $0 \%$
b) $2.5 \%$
c) $5.0 \%$
d) $7.5 \%$
e) $10.0 \%$

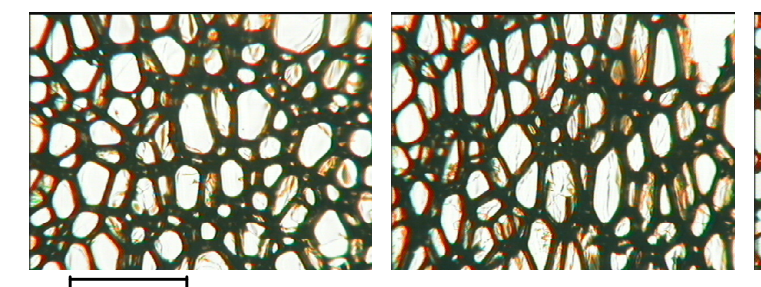

$0,5 \mathrm{~mm}$

f) $0 \%$

g) $2.5 \%$

i) $7.5 \%$

j) $10.0 \%$

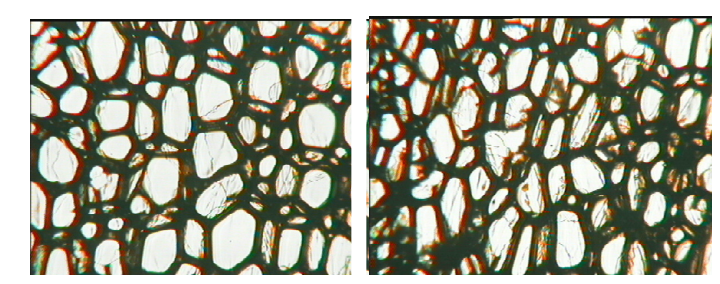

$0,5 \mathrm{~mm}$

k) $0 \%$

l) $2.5 \%$

n) $7.5 \%$

o) $10.0 \%$

Figure 1 Cell structure of modified PU/MMT foamed materials: a), b), c), d), e) perpendicular; f), g), h), i), j) parallel I; k), l), m), n), o) parallel II to the direction of foam's growth) 


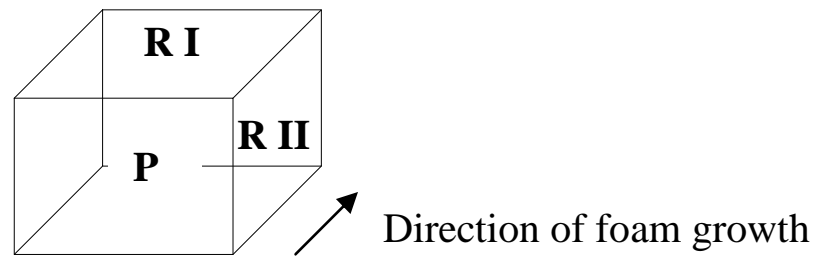

Figure 2 Test surfaces; $\mathbf{P}$ - perpendicular, RI and RII parallel to the direction of foam growth 


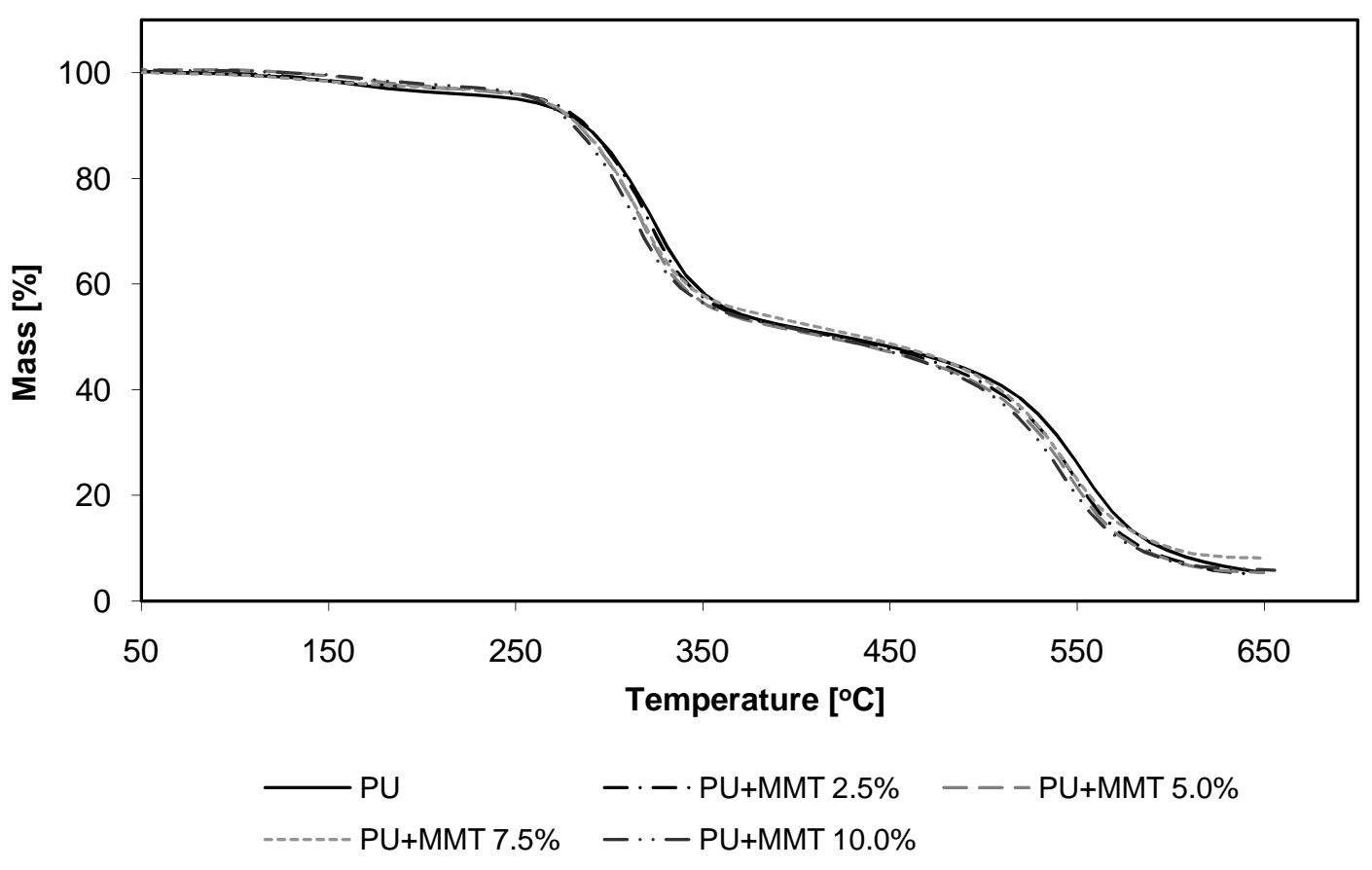

Figure 3 TG results for PU/MMT foams 


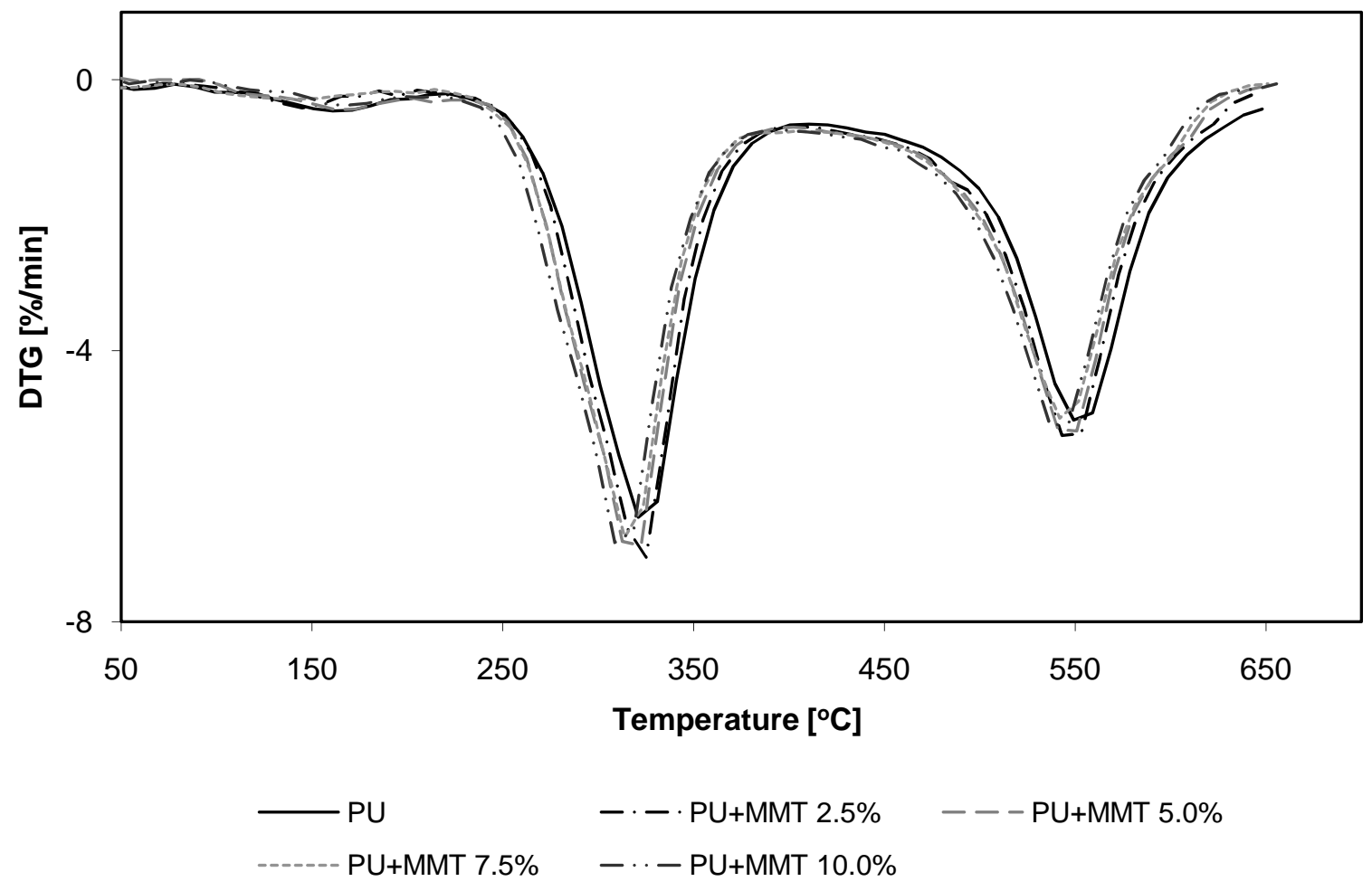

Figure 4 DTG curves for PU/MMT foams investigated 


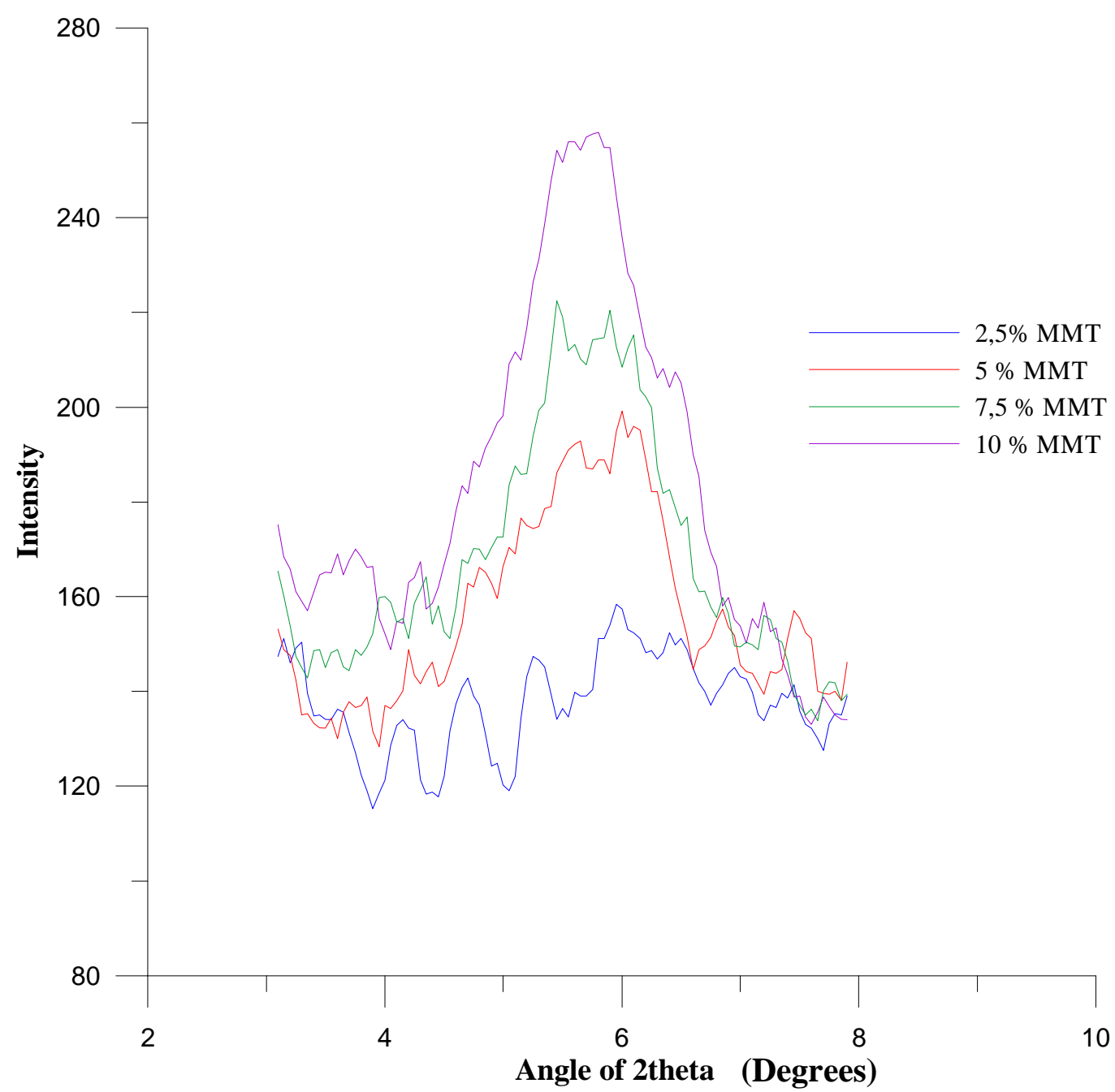

Figure 5 Diffraction patterns of the PU/MMT foamed nanomaterials. 


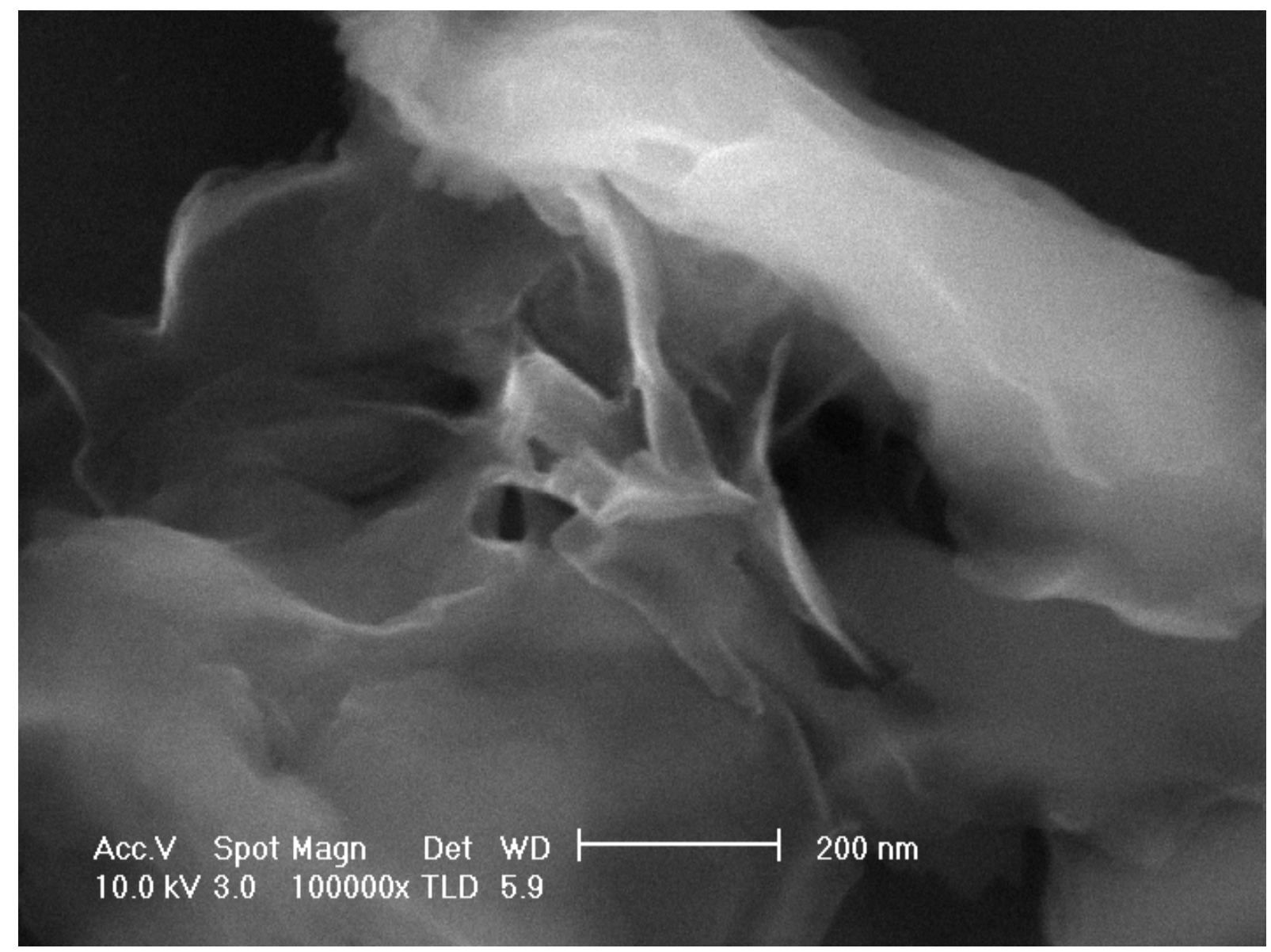

Figure 6 SEM microphotograph confirms that MMT is fully exfoliated in the PU matrix 


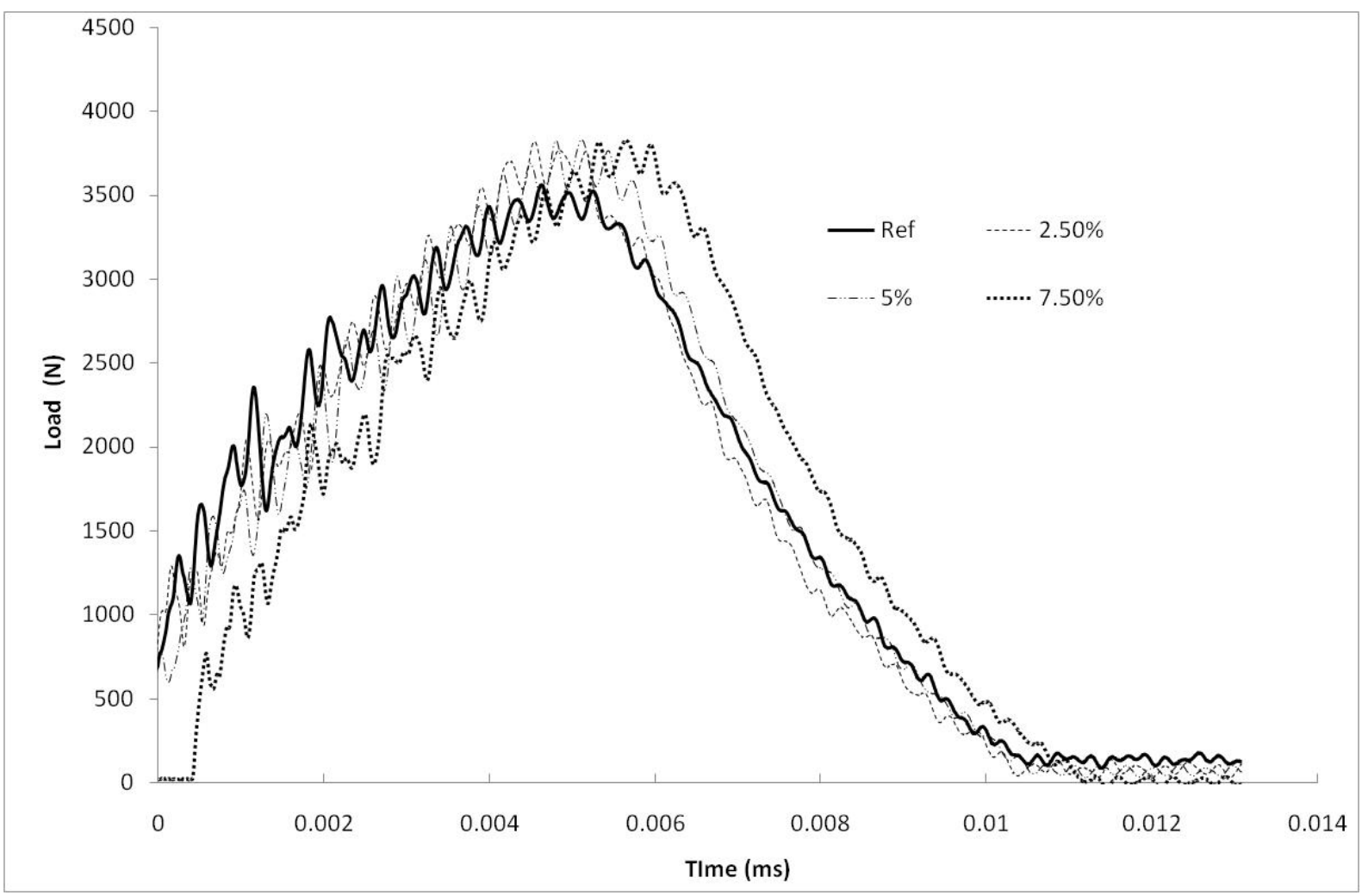

Figure 7 Comparison of load vs time graph obtained from first impact 


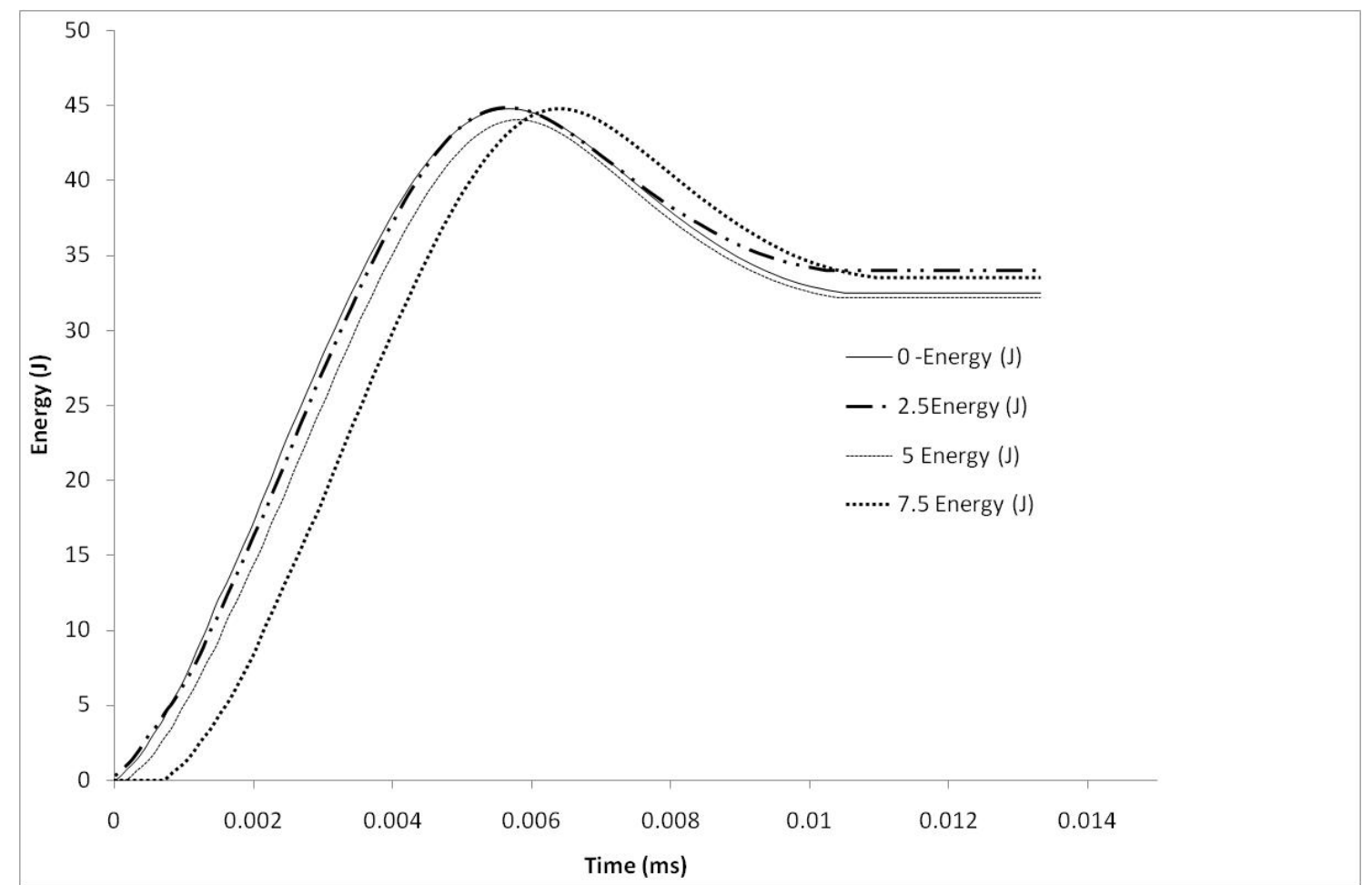

Figure 8 Energy vs time graph obtained from first impact 


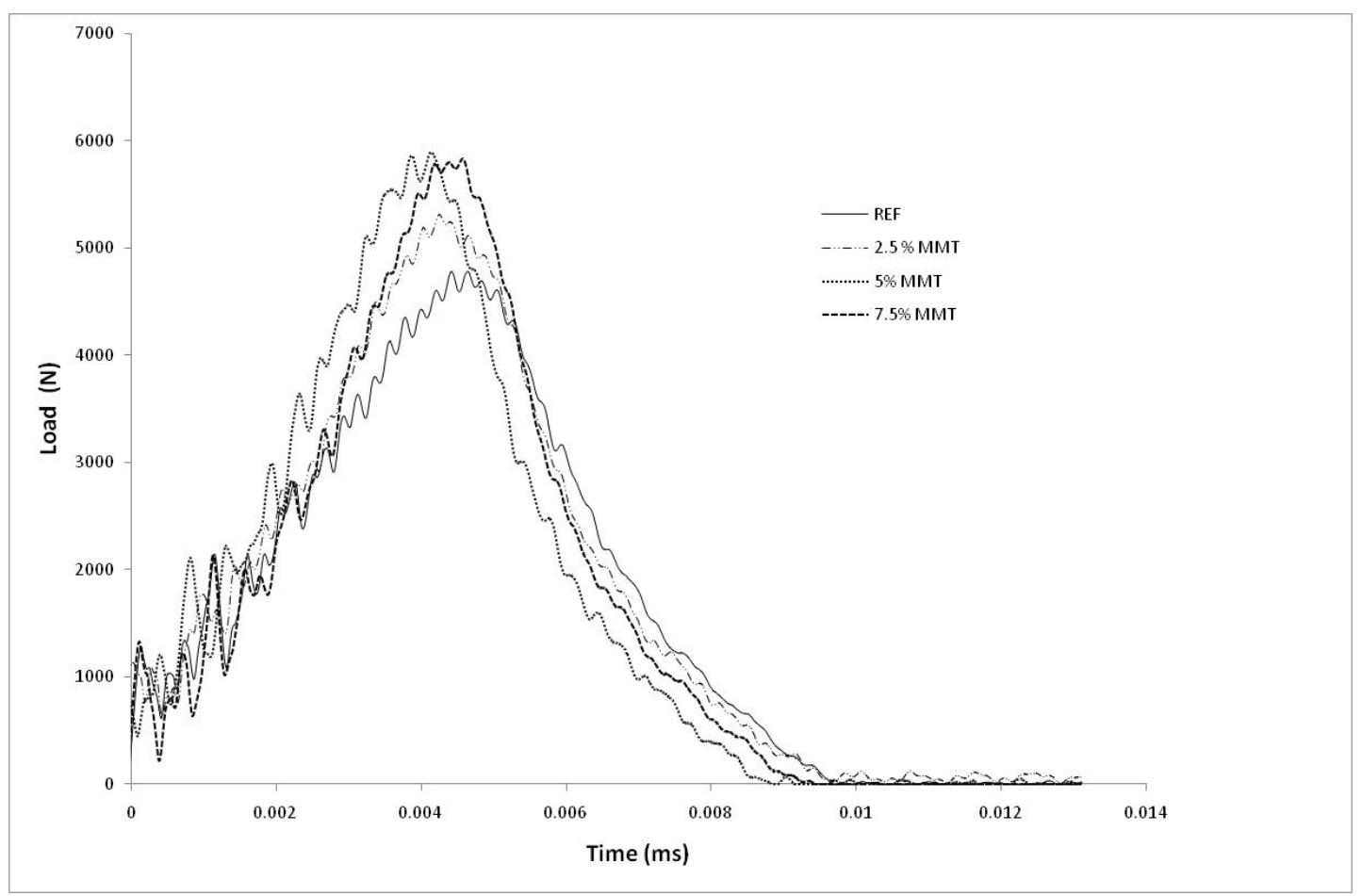

Figure 9 Load vs time graph obtained from second impact test 


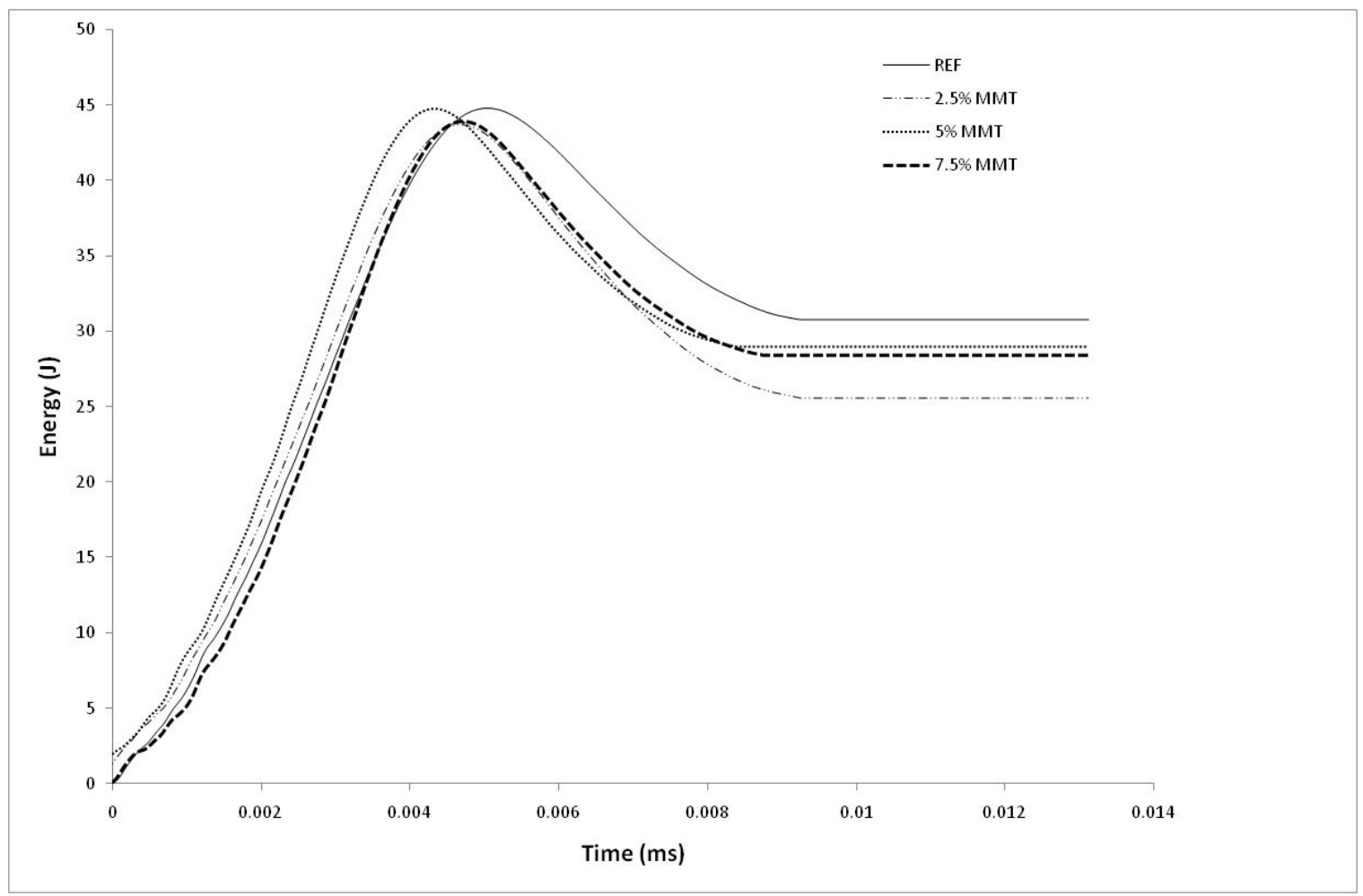

Figure 10 Energy-time graphs after second impact test 